\title{
EL USO DE PRINCIPIOS JURÍDICOS NO ESCRITOS POR LOS TRIBUNALES ${ }^{1}$
}

\section{Introducción}

Este artículo versa sobre los principios jurídicos que son aceptados por los tribunales como una fuente del Derecho, pero que no han sido impuestos por algo así como una ley o alguna otra fuente formal del Derecho.

No trataré la distinción entre reglas y principios como tal, ni la aplicación de los principios jurídicos que están explícitamente formulados en el Derecho.

Me centraré en los sistemas europeo continentales de Derecho codificado, dejando de lado la específica situación de los sistemas de Common Law.

El punto de partida se sitúa en el hecho evidente de que en las últimas décadas los tribunales de diversos países europeos han comenzado a formular y aplicar «principios generales del Derecho» para colmar lagunas del Derecho ${ }^{2}$ e incluso para «corregir» el Derecho legislado.

2. En la mayoría de sistemas jurídicos existe la obligación formal de los jueces de decidir todos los casos incluso cuando el Derecho imperante no dispone de regla aplicable ${ }^{3}$.

${ }^{1}$ Quiero agradecer a los siguientes colegas la ayuda, comentarios y/o información sobre el papel de los principios generales del Derecho en sus respectivos países: John Bell, Javier de Lucas Martín, Paulo Ferreira da Cunha, Alain Supiot y Ernesto Vidal.

2 En Bélgica desde la decisión de la Cour de Cassation (Hof van Cassatie) del diez de enero de 1950; en Francia desde la decisión Aramu del 26 de octubre de 1945 del Conseil d'Etat; en Holanda desde la ley de 20 de junio de 1963 que confería a la Corte Suprema (Hoge Raad) el poder de aplicar no sólo las leyes sino más generalmente «el Derecho».

${ }^{3}$ Por ejemplo: en Francia, art. 4 del Code civil: Le juge qui refusera de juger sous prétexte du silence, de l'obscurité ou de l'ínsuffisance de la loi, pourra être poursuivi comme coupable de déni de justice. En Suiza, art. 1 del Code civil: La loi régit toutes les matiè auxquelles se rapportent la lettre ou l'esprit de l'une de ses dispositions.

A défaut d'une disposition légale applicable, le juge prononce selon le droit coutumier et, à défaut d'une coutume, selon les règles qu'il établirait s'il avait à faire acte de législateur. Il s'inspire des solutions cansacrées par la doctrine et la jurisprudence. 
A veces el legislador da algunas guías o directivas relativas a la manera en que los jueces deberían decidir cuando se enfrentan con una laguna del sistema jurídico. Estas reglas se refieren implícita o explícitamente al uso de principios generales del Derecho no escritos [unwritten].

El art. 10, $3^{\circ}$ del código civil portugués, por ejemplo, formula al juez la directiva de actuar como un legislador «de acuerdo con el espíritu del sistema jurídico» (espirito do sistema). Ello implícitamente se refiere a algunos principios generales del Derecho.

En Italia el art. 12 de las Disposiciones sobre la ley en general establece de forma más explicita: «En la aplicación de la ley no se puede atribuir a la misma otro sentido que el que claramente se sigue del significado propio de las palabras, de las conexiones entre ellas y de la intención del legislador. Si una controversia no puede resolverse usando una precisa disposición, se tomarán en consideración las disposiciones que regulan casos similares o materias análogas; si a pesar de ello el caso permanece en duda, se decidirá según los principios generales del ordenamiento jurídico del Estado».

En España, el art. 1.1 del Título preliminar del Código civil enumera y jerarquiza las fuentes del Derecho: legislación, costumbre y principios generales del Derecho. En el art. 1.4. se lee «los principios generales del Derecho se aplicarán en defecto de ley o costumbre, sin perjuicio de su carácter informador del ordenamiento jurídico». Este artículo explícitamente alude al papel de los principios generales del Derecho como axiomas (ocultos) del sistema jurídico, con una finalidad (mucho) más amplia que la de simplemente colmar las lagunas del Derecho. El art. 1.7., finalmente, ordena a los jueces decidir todos los casos que se les presenten tomando en cuenta «el sistema de fuentes establecido».

3. Una variable interesante se encuentra en las reglas del Derecho Internacional que no confieren al juez un poder universal para formular principios generales y aplicarlos a un caso concreto, sino que se refieren a los principios comunes a los diferentes sistemas jurídicos nacionales.

Por ejemplo, el art. 215 del Tratado de la Comunidad Económica Europea de 1957 se refiere explícitamente a los «principios generales comunes a los Derechos de los Estados miembros» para determinar la responsabilidad no contractual de la Comunidad respecto de sus funcionarios.

El art. 38 del Estatuto del Tribunal Internacional de Justicia alude de manera más general a «los principios generales del Derecho reconocidos por las naciones civilizadas» como una de las fuentes del Derecho Internacional Público.

De acuerdo con el Derecho escrito, los principios generales del Derecho parecen tener, a primera vista, un alcance mucho más limitado en el Derecho europeo que en el Derecho Internacional Público. En la práctica, sin embargo, ocurre al revés. 
Debido a la diversidad de sistemas jurídicos y principios jurídicos existente en el mundo, difícilmente puede esperarse que el Tribunal Internacional de Justicia alcance un consenso sobre un conjunto de principios comunes, y menos aún cuando se es consciente del contexto político internacional y del limitado papel que juega este Tribunal.

Por el contrario, los principios generales del Derecho han llegado a ser mucho más importantes en las decisiones del Tribunal Europeo de Justicia de lo que cabía esperar sobre la base del limitado alcance que les otorgaba el art. 215 del Tratado de la CEE.

Como en los sistemas jurídicos nacionales europeos, el Tribunal Europeo formula y aplica principios generales delDerecho para colmar lagunas del Derecho Comunitario. Dado que estos principios son en parte inducidos de aquellos sistemas jurídicos nacionales, más que de elementos delDerecho escrito de la Comunidad Europea, el uso de los principios jurídicos tiene una dimensión comparativa ${ }^{4}$.

4. La mayoría de sistemas jurídicos (nacionales) como, por ejemplo, el francés, elalemán, el holandés o el belga, no cuentan con disposiciones legales que indiquen a los jueces cómo colmar las lagunas del Derecho. Precisamente en estos sistemas jurídicos es en los que el creciente uso de los principios jurídicos no escritos resulta más fascinante.

La aplicación judicial de reglas jurídicas no escritas para colmar lagunas del sistema jurídico ha evolucionado en la práctica hacia la aceptación de todo un conjunto de principios jurídicos no escritos, que son utilizados no sólo para colmar las lagunas del Derecho, sino también para limitar y reducir el alcance de las reglas jurídicas explícitamente formuladas en las leyes.

Esta práctica judicial plantea dos problemas principales. Primera cuestión: ¿dónde encuentran los jueces esos principios jurídicos, dado que no pueden hallarse en una fuente formal de Derecho? Segunda cuestión: ¿cómo justifican estos jueces su práctica cuando limitan la aplicación del Derecho escrito porque entra en conflicto con unos bastante vagos principios generales que nunca han sido formulados por el legislador? ¿Cuál es la relación entre la interpretación jurídica tradicional y el uso de principios jurídicos no escritos?

Otra cuestión que surge es la de cómo puede explicarse este incremento en el uso de los principios jurídicos no escritos por parte de los tribunales.

Finalmente, habría que examinar hasta qué punto la práctica judicial de aplicar principios jurídicos no escritos puede encajar dentro de una teoría jurídica coherente.

4 Kötz, H.: «Allgemeine Rechtsgrundsätze als Ersatzrecht», Rabels Zeitschrift für ausländisches und internationales Privatrecht, 1970, 671. 


\section{Formulación y (re)construcción de principios jurídicos por los jueces.}

5. En términos generales pueden distinguirse dos tipos de principios jurídicos no escritos que son aplicados por los tribunales.

Por un lado, los que podríamos llamar «principios estructurales», que son los que se inducen, o al menos se pretende que son una derivación, del Derecho escrito.

Por otro lado, los que podríamos llamar «principios ideológicos» que no son el resultado de una inducción a partir del sistema jurídico vigente. Se refieren a creencias morales, políticas o a creencias relativas a otras ideologías no jurídicas dominantes en una sociedad.

(a) Principios jurídicos estructurales.

6. En cierto sentido los principios estructurales son axiomas ocultos de la estructura lógica del sistema jurídico o de alguna rama del mismo. Su aceptación es necesaria o al menos deseable para la coherencia (óptima) del sistema jurídico. Estos principios están implícitamente presentes en el sistema jurídico, incluso en el caso de que el legislador nunca haya sido claramente consciente de su existencia.

Algunos ejemplos:

- En varios países europeos, el principio general de la «buena fe» se ha inducido de una o varias reglas concretas, como por ejemplo la de la obligación de ejecutar los contratos de acuerdo con la buena fe. Este ha sido el caso de Italia, donde el principio general de la buena fe se ha inducido de esta regla, formulada en el 1337 del Código Civil y de otros artículos como el 128 y el $1192^{5}$. En Bélgica la misma regla está establecida en el art. 1134 del Código civil y los tribunales la han generalizado. En el Derecho finlandés también el principio general de la buena fe se ha derivado del principio de lealtad del Derecho de contratos ${ }^{6}$. Lo mismo ha sucedido en Alemania, donde el principio está basado en el parágrafo 242 del BGB.

En España, donde el art. 1258 del Código civil contiene una regla semejante, el principio general de buena fe, sin embargo, está establecido en el mismo Código: «Los derechos deberán ejercitarse conforme a las exigencias de la buena fe» (art. 7.1 del Título preliminar del Código Civil).

- La fuerza obligatoria de los contratos o de los tratados internacionales puede deducirse de la propia naturaleza de estos acuerdos.

${ }^{5}$ Pattaro, E., «La completitud de los ordenamientos jurídicos y los "principios generales del ordenamiento jurídico del Estado”», Anuario de Filosofia Jurídica y Social (Buenos Aires), 1986, pág. 204-305.

6 Aarnio, A., «Taking Rules Seriously», en Kangas, U. (ed) Enlightenment, Rights, Revolution (IVR Edinburgo, 1989), Helsinki 1989, pág. 5, con referencia a Pöyhönen, J., Sopimusoikeuden järjestelmä ja sopimusten sovittelu, Helsinki, 1988, 79. 
- En el Derecho civil esta fuerza obligatoria es una consecuencia necesaria de la función que se atribuye a los contratos en nuestra sociedad y más específicamente en nuestro sistema económico.

- En Derecho internacional el principio «pacta sunt servanda» puede ser considerado como una necesidad lógica a priori que es inherente al concepto de «tratado». En algún sentido es la Grundnorm del Derecho internacional.

- La imparcialidad de los jueces se sigue de la naturaleza de la función judicial.

- La prohibición de tomarse la justicia por su propia mano puede derivarse del concepto de Estado de Derecho que implica el monopolio de las autoridades para imponer el Derecho.

- La prohibición de discriminación económica y el principio de libertad económica se sigue de los propios cimientos del orden jurídico de la Comunidad Europea.

\section{(b) Los principios jurídicos ideológicos.}

7. Algunos de los ejemplos arriba expuestos a propósito de los principios estructurales tienen una naturaleza claramente ideológica (como el principio de la buena fe). Sin embargo, son estructurales porque encuentran «apoyo institucional» ${ }^{7}$ en los códigos y en las leyes. Puede argumentarse que estos principios generales han sido aceptados al menos implícitamente por el legislador, dado que este último los ha aplicado en una o varias reglas concretas.

Los principios jurídicos ideológicos no cuentan con este apoyo institucional. Resultan de la aplicación por los tribunales de valores o normas no jurídicos.

Ejemplos de estos principios son los siguientes, al menos en el Derecho belga:

- La prohibición del abuso de Derecho.

- El principio de razonabilidad aplicado al uso de poderes discrecionales por parte de las autoridades.

- El principio de seguridad jurídica.

En el ámbito del Derecho Europeo podría pensarse en el principio de igualdad del Derecho de la Comunidad Europea ${ }^{8}$.

8. En la práctica, y por lo general, los principios ideológicos sólo se aplican para restringir la aplicación de ciertas reglas jurídicas. «Corrigen» aplicaciones de reglas que se considera que bajo ciertas circunstancias específicas

\footnotetext{
7 Para el concepto de «apoyo institucional», véase Aarnio, A., ob. cit., 1. c., con referencia a Hannu
} Tolonem.

8 En la mayoría de países europeos este principio está establecido en fuentes formales de Derecho, particularmente en el Art. 14 del Tratado de Roma. Sólo dentro del sistema jurídico de la Comunidad Europea es un principio puramente ideológico. 
pueden resultar claramente injustas, irrazonables o inaceptables desde ciertos puntos de vista ideológicos comúnmente aceptados. Operan en el contexto de una revisión judicial [judicial review] limitada. Sólo cuando la regla jurídica entre claramente en conflicto con un principio moral o político generalmente aceptado entonces se dejará de lado la regla y se aplicará el principio no-jurídico en la forma de un -recién formulado- principio general del Derecho.

Los principios jurídicos estructurales tienen generalmente un alcance más amplio que los ideológicos. Esto les hace ser principios guía, mientras que los principios ideológicos operan siempre como principios correctores.

Antes de tratar de explicar el creciente y presente papel de los principios generales no escritos en la aplicación del Derecho por los tribunales, necesitamos comparar esta práctica con la práctica más tradicional de la interpretación del Derecho.

\section{Los principios jurídicos y la interpretación de las leyes}

\subsection{La interpretación por analogía}

9. Podría sostenerse que la interpretación por analogía no es otra cosa que una aplicación camuflada de principios generales del Derecho no declarados. Cuando se razona por analogía, el intérprete aplica una regla jurídica a un caso que como tal no cae dentro del alcance de esa regla pero que en los puntos principales dicho caso es semejante a aquellos en los que la regla resulta claramente aplicable. Dicho en otras palabras: para proceder desde un caso al que la regla le es claramente aplicable a otro considerado semejante se va desde un principio jurídico más general, el cual se aplica posteriormente al caso no cubierto por la regla9 .

Es un hecho que en el siglo doce los glosadores derivaban principios jurídicos generales (regulae iuris) a partir de razonamientos por analogía. Pattaro cita un ejemplo tomado de Bulgarus, uno de los más importantes glosadores de Bolonia: El pescado pertenece al pescador. Cuando un cazador caza animales y aves que viven en libertad pertenecen al cazador. De estos casos análogos el glosador deriva el principio general que afirma que una res nullius se convierte en propiedad del primero que la toma ${ }^{10}$.

9 Van Gerven, W., Beginselen van Belgisch Privaatrecht. Algemeen Deel, Antwerpen 1969,58; Foriers, P., «L'interprétation par analogie en droit belge» en La pensée juridique de, Paul Foriers, Bruselas, 1982, II, 817, 818; Zippelius, R., Einführung in die juristische Methodenlehre, Munich, 1971, 74; Gerard, Ph., Droit, égalité et ideologie. Contribution à l'étude critique des principes généraux du droit, Bruselas, 1981, 184.

10 Pattaro, E., «Les principes généraux du droit entre raison et autorité», en Vassart, P. (ed.), Arguments d'autorite et arguments de raison, Bruselas, 1988, p. 282. Véase también: Stein, P., Regulae iuris: From Juristic Rules to Legal Maxims, Edimburgo. 1966, p. 49-130. 
En términos generales, puede concluirse que la interpretación por analogía ha sido tradicionalmente la técnica más usada para colmar las lagunas del Derecho ${ }^{11}$.

10. La jurisprudencia alemana distingue la «analogía legis» (Gesetzesanalogie) de la más general «analogía iuris» (Rechtsanalogie).

La «analogía legis» denota un razonamiento por analogía que parte de un único texto legal, mientras que la «analogía iuris» designa un razonamiento por analogía conforme al cual un principio más general es inducido desde varios textos legales ${ }^{12}$. Este último caso en particular es muy parecido al «razonamiento de principios generales» (cuando se usan principios estructurales), aunque en ocasiones los principios se inducen de una única regla jurídica. En este punto surge la cuestión de si los tribunales, al menos por lo que se refiere a los principios estructurales, no podrían haber alcanzado los mismos resultados utilizando la técnica más tradicional de la interpretación por analogía, en lugar de introduciendo una nueva fuente del Derecho. Si la respuesta es que sí, habrá que preguntarse qué ventajas presenta esta nueva aproximación en comparación con la metodología tradicional de la interpretación. Trataré de responder a estas cuestiones en la «conclusión» de este trabajo.

\section{2. La interpretación teleológica}

11. El razonamiento por analogía está muy cerca de la interpretación teleológica, en el sentido de que en ambos casos se busca un propósito más general de la regla. La analogía se funda en un nivel más abstracto del propósito (común). Aunque el propósito de una regla y el principio general que está detrás de la regla no son lo mismo, ambos están en el mismo meta-nivel, encima o detrás de la regla. En ambos casos este meta-nivel de información es usado para formular una regla concreta.

12. Dentro del método de la interpretación teleológica también puede distinguirse entre «teleología legis» (Gesetzesteleologie) y la más amplía «teleología iuris» (Rechtsteleologie) ${ }^{13}$.

Quien recurre a la teleología legis se enfrenta al propósito concreto que perseguía el legislador al dictar el texto en cuestión; el propósito de la ley en general y/o el propósito del artículo interpretado.

El intérprete que recurre a la teleología iuris no se concentra en la intención concreta del legislador, que es un producto de su tiempo, sino en propósitos más abstractos y en principios que conforman las bases de todo

11 Foriers, P., «L'interprétation per analogie en droit belge», en: La pensée juridique de Paul Foriers, Bruselas, 1982, II, 817. Véase también el art. 12 de las disposiciones italianas sobre el Derecho en general antes citado.

${ }^{12}$ Esser, J., Vorverständnis und Methodenwahl in der Rechtsfindung, Frankfurt, 1972, 185.

${ }^{13}$ Van Hoecke, M., Norm, Kontext und Entscheidung, Acco, Leuven, 1988, pág. 204-211. 
el sistema jurídico o de parte de él. Estos propósitos y principios están relacionados con ideologías generales dominantes en la sociedad.

A modo de ejemplo, quiero citar un caso del Derecho de la seguridad social belga.

Un «amo de casa» reclamó una pensión a la seguridad social sobre la base de una ley que se refería sólo a las «amas de casa» ${ }^{14}$. El tribunal laboral de Amberes accedió a su petición argumentando que el legislador recientemente había dictado en otras ramas del Derecho un conjunto de disposiciones legales que apuntaban hacia el tratamiento igual de hombres y mujeres ${ }^{15}$.

13. Mientras que la interpretación llamada teleología legis puede aplicarse sin una vinculación directa con los principios generales del Derecho, ello no es así en la interpretación llamada teleología iuris. Este último método difícilmente puede distinguirse de la actual formulación y uso de principios generales por los tribunales.

Utilizando la distinción que Ronald Dworkin traza entre «directriz»y «principio» ${ }^{16}$, podemos concluir que la interpretación que hemos llamado teleología legis sitúa el texto legal en el contexto de la «directriz» o propósito concreto del legislador, mientras que la teleología iuris tiende a caer sobre los principios, tomando menos en cuenta las directrices concretas o propósitos del legislador en un momento histórico determinado.

\section{Texto legal, regla, principio y teoría política}

14. La teoría del Derecho ha repetido una y otra vez que regla jurídica y texto legal no son lo mismo. El texto suministra información sobre la regla, pero no es la regla misma. Esta es precisamente la razón por la que la interpretación del texto de una ley puede producir un resultado que puede desviarse de, o incluso ser opuesto a, lo que es su significado prima facie. Piénsese en el ejemplo anterior en el que un «amo de casa» era considerado «una ama de casa».

Naturalmente, para un sistema jurídico es deseable que haya un máximo de sincronía entre, por un lado, las reglas tal como las quería el legislador y, por otro, los significados prima facie de los textos de las leyes tal como

${ }^{14}$ Art. 165, 1, $1^{\text {o en }} 2^{\text {o }}$ Koninklijk Besluit (Real decreto) de 4 de noviembre de 1963.

15 Arbeidsrechtbank Antwerpen, 26 de junio de 1979, Rechtskundig Weekblad 1979-80, 1963.

16 Dworkin define un principio jurídico como «un estándar que ha de ser observado, no porque favorezca o asegure una situación económica, política o social que se considera deseable, sino porque es una exigencia de la justicia, la equidad o alguna otra dimensión de la moralidad». Como ejemplo de principio da el de que «nadie puede sacar provecho de su propia injusticia». Una directriz, por otro lado, es «aquel tipo de estándar que propone un objetivo que ha de ser alcanzado, generalmente una mejora en algún rasgo económico, político o social de la comunidad». Por ejemplo, «reducir el número de accidentes de tráfico». Dworkin, R., Taking Rights Seriously, Londres, 1978, 22. 
son realmente leídos por los juristas. La perfección, sin embargo, nunca puede alcanzarse, en parte debido al desarrollo de la sociedad y a la tremenda cantidad de legislación.

15. Debido a que existe esa necesidad de buena sincronía entre el texto legal y la regla jurídica, las reglas jurídicas necesitan estar en sincronía con los principios jurídicos más básicos, aquellos que son el fundamento de las concepciones jurídicas, de las ramas del Derecho o de todo el sistema jurídico.

16. Los principios jurídicos tampoco pueden ser arbitrarios. Deben ser coherentes, deben encuadrarse dentro de una ideología coherente, en una teoría política no contradictoria. Tal teoría debería contener no sólo un número de principios compatibles sino también algunos meta-principios que indicasen qué principios elegir cuando dos de ellos entrasen en conflicto en un caso concreto.

Un ejemplo es el equilibrio entre el principio de respeto a la soberanía nacional y el principio de respeto a los derechos humanos. Estos principios entran en conflicto, por ejemplo, cuando se aplican a la actual intervención internacional en el Kurdistán iraquí.

En los sistemas jurídicos nacionales, por ejemplo, la libertad de expresión en ocasiones puede entrar en conflicto con el derecho a la intimidad.

El hecho de que estos principios sean ampliamente aceptados en una comunidad no es suficiente. En caso de conflicto se necesita un nuevo meta-principio que pueda decidir cuál de los dos principios debería tener prioridad en el caso concreto. Pero frecuentemente se trata de casos difíciles por lo que no es fácil encontrar un meta-principio comúnmente aceptado. E1 problema no puede, sin embargo, ser sorteado. Si no hay respuesta clara a la cuestión del meta-principio, se debería al menos partir de los «principios procedimentales» comúnmente aceptados, lo que significa utilizar principios jurídicos que se reconocen como fundamentos para la toma de decisiones en la práctica, o dar alguna preferencia a la teoría más coherente ${ }^{17}$.

\section{Los principios generales como «ius commune»}

17. En algunas ocasiones la emergencia de los principios generales del Derecho como una nueva fuente del Derecho ha sido considerada algo así como un resurgimiento del Derecho natural. En opinión de Paul Orianne es una alternativa a la pérdida del Derecho natural, pero dentro de los sistemas de Derecho positivo ${ }^{18}$. Chaïm Perelman, por su parte, afirma que podría explicarse como una reacción antipositivista de los tribunales después de la Segunda Guerra Mundial ${ }^{19}$.

\footnotetext{
${ }^{17}$ Cfr. Aarnio, A., ob. cit., pág. 13.

${ }^{18}$ Orianne, P., Introduction au système juridique, Bruselas, 1982, pág. 75.

19 Perelman, Ch., Logique juridique. Nouvelle rhétorique, Paris, 1976, pág. 137.
} 
No está claro si ésta debería considerarse la explicación principal de la emergencia de los principios jurídicos en la práctica judicial de muchos países europeos. En mi opinión, es mucho más una forma de tomar en cuenta la importancia actual de los derechos humanos en la práctica política y jurídica. Desde las codificaciones del siglo diecinueve el Derecho natural no ha jugado ningún papel directo en las decisiones de los tribunales. En nuestros días además los principios generales del Derecho no cumplen una función crítica como piedra de toque de la moralidad de los sistemas jurídicos. Como mucho, los principios jurídicos ideológicos son simplemente una limitación de los propósitos (prima facie) de algunas reglas jurídicas. Los principios jurídicos estructurales en realidad no pueden entrar en conflicto con el sistema jurídico, pues se extraen de elementos de este sistema. Por otro lado, los derechos humanos están jugando un creciente papel crítico. Realmente funcionan como un sistema de Derecho natural, incluso en el caso de que hayan llegado a formar parte del Derecho positivo, como es el caso, por ejemplo, del Tratado de Roma. Los derechos humanos son considerados en efecto como inherentes a todo ser humano, existen a priori, independientemente de la voluntad o benevolencia de un legislador. Son el Derecho natural del presente que fundamenta la crítica a los sistemas políticos y jurídicos y a las prácticas políticas y jurídicas. Comparado con el estatus jurídico positivo de los principios generales del Derecho, el hecho de que los derechos humanos estén establecidos en tratados internacionales tiene un valor mucho más simbólico y político que de estatus jurídico positivo.

18. Aun así, hay un claro paralelismo entre derechos humanos y principios generales del Derecho. El hecho de que, durante las últimas décadas, estos principios hayan sido cada vez más formulados y aplicados por los tribunales para completar, sofisticar y corregir el Derecho legislado significa que esta práctica satisface ciertas necesidades. No está muy claro qué elementos precisos han influido en esta práctica, pero ciertamente ella satisface hasta cierto punto una resurgida necesidad de un armazón ético para el Derecho. Sin lugar a dudas, ello es así en el caso del incremento de la importancia de los derechos humanos, y claramente también de los principios jurídicos ideológicos y, en cierta medida, de la carga ética de los principios jurídicos estructurales.

19. Sin embargo, el desarrollo de los principios jurídicos estructurales no puede explicarse por este resurgimiento de la ética. Una hipótesis mucho más plausible consiste en considerar la fragmentación del Derecho como la explicación principal del incremento de los principios jurídicos (estructurales). Dadas las dimensiones del número de reglas, el número de normas que entran en conflicto crece inevitablemente y, en consecuencia, la demanda de criterios que permitan resolver dichos conflictos de normas. La formulación y el uso de principios generales del Derecho satisface esta necesidad. A través de estos principios generales se desarrolla un nuevo ius commune. 
Con anterioridad a las codificaciones del siglo diecinueve, en muchos países europeos el Derecho romano jugaba un papel unificador frente a la fragmentación que representaba el Derecho consuetudinario local. ElDerecho romano aportaba la generalidad, los conceptos y los principios unificadores. En la medida en que las costumbres locales los derogaban, éstas eran interpretadas en sentido restringido (1).

Las codificaciones, particularmente el Código civil francés de 1804, fueron una síntesis de Derecho consuetudinario, Derecho romano y los nuevos principios de la revolución burguesa. Después de eso, por primera vez en la historia, los principales principios jurídicos fueron establecidos en la legislación y más precisamente en el código civil.

El incremento de legislación al margen de los códigos, la secesión de nuevas ramas del Derecho, tales como el Derecho social, con un propósito propio y una ideología subyacente diferente, ha dificultado sobremanera el uso del código civil como un ius commune que cumpla la función de coordinar todo el Derecho.

Así, a lo largo (de la segunda mitad) del siglo veinte se ha ido desarrollando un nuevo ius commune, en la forma de un -todavía creciente y sofisticado- conjunto de principios generales del Derecho. Estos principios jurídicos funcionan hoy en día como «reglas de clausura», esto es, como reglas que garantizan la coherencia y la completitud del sistema jurídico.

En este sentido, escribe Huberlant: «...il y a donc entre les règles d'un même système de droit non seulement une cohérence excluant la contradiction, mais aussi une harmonie qui découle de l'esprit général qui anime le système et se manifeste par la concordance des solutions choisies... C'est donc l'harmonie d'un système juridique qui justifie la démarche du juge qui s'estime en mesure de remonter des règles particulières constituant ce système jusqu'aux principes généraux qui l'animent, même si ceux-ci ne sont exprimés par aucun texte; et c'est pour assurer le maintien et favoriser le développement de l'harmonie du système juridique que le juge, en l'absence de texte, invoque directement ces principes généraux» ${ }^{20}$.

\section{Conclusión}

20. Quiero repetir brevemente las conclusiones relativas a los temas que he discutido y añadir algunos comentarios.

Creo que la distinción entre principios jurídicos estructurales y principios jurídicos ideológicos puede ser un elemento importante para la elaboración de una teoría de los principios jurídicos, dado que estos dos tipos de principios responden a necesidades diferentes y juegan papeles distintos en la práctica jurídica.

20 «Huberlant, Ch., «Antinomies et recours aux principes généraux», en Les antinomies en droit. Perelman, Ch. (ed.), Bruselas, 1965, 212. 
Los principios estructurales generalmente se usan praeter legem, los principios ideológicos contra legem.

Mientras que los principios jurídicos estructurales en general son principios guía y tienen un alcance amplio, los principios ideológicos sólo se utilizan como principios de corrección y se aplican dentro del marco de una limitada revisión judicial.

Los principios jurídicos estructurales primariamente satisfacen la necesidad de un nuevo «ius commune» con el fin de alcanzar la coherencia y la completitud del sistema jurídico, mientras que los principios jurídicos ideológicos, igual que los derechos humanos, satisfacen una resurgida demanda de un armazón ético para el Derecho.

El alcance de los principios jurídicos estructurales se limita muchas veces a ciertas ramas del Derecho, por ejemplo, el Derecho administrativo o el Derecho procesal por mencionar dos ramas en las que los principios jurídicos se aplican ampliamente, mientras que los principios ideológicos son válidos para todo el sistema jurídico.

Puede hacerse una última distinción entre «principios que establecen objetivos» [aim principles] y «principios que establecen medios» [means principles]. Los principios que establecen medios son medios para implementar un principio más general que establece un objetivo. Por ejemplo, el principio del derecho a una segunda instancia cuando un caso ha sido decidido por un tribunal es un medio para alcanzar el principio más general de derecho a la defensa. El principio de pasividad del juez es un medio para alcanzar el principio de neutralidad del juez.

El principio patere legem quam ipse fecisti es un medio para alcanzar el principio de igualdad que es más amplio. La prohibición de dictar normas retroactivas es un medio para alcanzar el principio de seguridad jurídica.

Van Orshoven argumenta incluso que todos los principios están implicado por un principio más general: el del Estado de Derecho ${ }^{21}$.

Es evidente que en algunos de estos ejemplos el principio más general, ideológico, que establece un objetivo se implementa dentro de una rama del Derecho específica a través de la formulación de un principio-medio.

Las distinciones entre principios que establecen objetivos y principios que establecen medios, por un lado, y entre principios de una rama del Derecho y principios válidos para todo el sistema jurídico, por otro lado, será útil para el desarrollo de la estructura jerárquica de los principios jurídicos.

Personalmente creo que tal teoría debería dejar espacio para una cierta autonomía ideológica de las diferentes ramas del Derecho. Aceptar esto significa que la coherencia completa sólo puede alcanzarse en el nivel de las ramas del Derecho, no en el nivel de todo el sistema jurídico.

${ }^{21}$ Van Orshoven, P., «Non scripta, sed nata lex», en Alkgemeine Rechtsbeginselen, Van Hoecke, M. (ed.), Kluwer Rechtswetenschappen, Antwerpen, 1991, pág. 74. 
21. Finalmente tenemos que responder a la pregunta de cómo puede justificarse el uso de principios generales del Derecho por parte de los tribunales.

Los principios jurídicos estructurales se inducen del sistema jurídico mismo y por tanto cuentan con un apoyo institucional bastante fuerte.

Aunque casi siempre podría obtenerse el mismo resultado recurriendo a la tradicional interpretación por analogía y/o interpretación teleológica, el uso de principios generales del Derecho presenta una gran ventaja: los principios tienen un alcance más amplio. Las interpretaciones concretas sólo suministran una decisión para un caso concreto, toman en cuenta los elementos específicos del caso. La interpretación individualiza la decisión judicial. El uso de principios generales, por el contrario, generaliza la decisión judicial. Esta generalización ofrece una oportunidad mucho mejor para estructurar estos principios en una teoría coherente. Los principios, mucho mejor que las interpretaciones individualizadas de leyes concretas, pueden ser ampliamente discutidos entre los juristas e incluso entre un público más amplio. De este modo tienen más posibilidades de contar con un amplio consenso, lo que consecuentemente les proporciona otro tipo de apoyo institucional.

Los principios ideológicos, por su parte, no se inducen del sistema jurídico. Son principios ideológicos no-jurídicos que los jueces transforman en jurídicos. Esta práctica podría justificarse, en primer lugar, sosteniendo que es inevitable una cierta adaptación y sofisticación del Derecho por parte de los jueces y que ello, desde el punto de vista del funcionamiento fluido del sistema jurídico, es necesario. En segundo lugar, aceptando que las dos siguientes condiciones deberían ser satisfechas: a) los principios ideológicos solamente deberían usarse dentro del marco de una limitada revisión judicial, para corregir reglas jurídicas (prima facie); b) deberían contar con un amplio consenso en la sociedad y/o (al menos) entre los juristas. Esta es la única manera en que los principios ideológicos no escritos pueden conseguir apoyo institucional. 
DOXA 19 (1996) 